\title{
Fish skin acellular dermal matrix: potential in the treatment of chronic wounds
}

This article was published in the following Dove Medical Press journal: Chronic Wound Care Management and Research

\section{Munir Patel John C Lantis II}

Department of Vascular Surgery, Mount Sinai St. Luke's-West Hospital Center, New York, NY, USA
Correspondence: Munir Patel Department of Vascular Surgery, Mount Sinai St. Luke's-West Hospital Center, 1090 Amsterdam Avenue, I2th Floor, New York, NY 10025, USA

$\mathrm{Tel}+\mathrm{I} 2125234797$

Fax + I 2125234720

Email Munir.patel@mountsinai.org

\begin{abstract}
The role of cellular and tissue-based therapies (CTPs) in the treatment of chronic wounds continues to grow. However, the utility of these is only partially investigated and very few head-to-head studies exist. In general, the ideal CTP would provide a structural matrix which would allow for dermal and epidermal regeneration with a single application. At present, this Holy Grail is very far from where we are. However, new CTPs continue to be designed with the goal of wound closure in mind. Acellular fish skin (AFS) is one such therapy. The histologic features make it amenable to cellular modulation, and its ability to provide omega- 3 fatty acids to the local tissue makes it an unprecedented anti-inflammatory, antibacterial, antiviral, and analgesic component. There is burgeoning research on AFS that continues to validate its efficacy, although, much more substantial data will be required before its general acceptance. In this review, we will go through the current literature to evaluate the strengths and gaps in our current knowledge with the goal of providing a context for use in modern clinical practice.
\end{abstract}

Keywords: fish skin, chronic wounds, dermal matrix

\section{Introduction}

The role of cellular and tissue-based therapies (CTPs) in the treatment of chronic wounds continues to grow. However, the utility of these is only partially investigated and very few head-to-head studies exist. In general, the ideal CTP would provide a structural matrix which would allow for dermal and epidermal regeneration with a single application. At present, this Holy Grail is very far from where we are. Currently, there are broadly three categories of CTPs; they are the ones that combine living cells and a collagen matrix, extracellular matrices (ECMs), and amniotic tissues. The living cellular therapies functionally allow for the deposition of growth factors and beneficial cytokines. Early on, these showed great promise; they were used in a host of injuries including acute wounds. Unfortunately, few large-scale studies were done and the ones that were done successfully directed these therapies to treat venous leg ulcers and diabetic foot ulcers. ${ }^{1-3}$ The amniotic tissues fundamentally call in mesenchymal precursor cells, and generally require frequent applications.

However, functional skin cannot be created without a functional ECM. There are three methods to enhance the ECM function in a wound: protect against the degradation of ECM, enhance its deposition, and replace it out of the box. Of the three methods, to replace it out of the box is the most clinically useful. There are broadly three categories of ECMs that one can apply right off the shelf. They are made up of xenografts (from 
nonhuman sources), allografts, and bioengineered products. Within the subset of xenografts, there is a continuum from modulatory ECMs to scaffold ECMs. One can think of these as products that require frequent application (weekly) and modulate the chronic wound environment to ones that only require one application and become highly incorporated into the wound bed. No ECM is completely one or the other, but ECMs may lean one way or the other. An example of a modulatory ECM, possibly with unique properties, is a xenograft composed of North Atlantic cod fish skin which is naturally rich in omega-3 fatty acids (acellular fish skin, AFS) (Figure 1).

\section{AFS origin and properties}

AFS is remarkably similar to human skin, yet fundamentally different from mammalian-derived matrices, because of the preservation of structure, lipids, and other soluble components. ${ }^{4}$ Mammalian scaffolds require harsh chemical processing to reduce viral and prion transmission risk; such risk from the Atlantic cod (Gadus morhua), found mainly in the salt waters of the Atlantic ocean, is nonexistent. Fish skin grafts are therefore subjected to gentle processing where structure and bioactive composition, including omega-3 polyunsaturated fatty acids, are preserved. ${ }^{5}$ Studies have shown that omega-3 fatty acids possess antiviral/antibacterial properties and also act as regulators of inflammation. ${ }^{6-8}$
Acellular mammalian-derived products possess prolonged shelf life compared to cellular skin substitutes, but, per US Food and Drug Administration (FDA) requirements, have to undergo "viral inactivation". Viral inactivation is performed with detergents that remove all soluble components from the tissue leaving behind an inert matrix of collagenous structure. The harsh viral inactivation processing removes lipids, glycans, elastins, hyaluronic acid, soluble collagen, and other important biologic components from the tissue that are potentially beneficial to wound healing. ${ }^{9}$ The fish skin graft has been used to treat a large number of wounds of various etiologies, both acute and chronic. ${ }^{10,11}$

For the purpose of this paper, we will review the literature related to AFS, while trying to place it the context of this study. When possible, we will make connections between the clinical and basic science, while relaying some practical pearls.

\section{Prospective double-blind controlled trials in an acute forearm punch biopsy model}

Like most ECMs, AFS had to go through the $510(\mathrm{k})$ process which is an FDA regulatory pathway that states that a device is "substantially equivalent" to a predicate device (one that has been cleared by the FDA or marketed before 1976). Most ECMs demonstrate similarities to porcine submucosa. In total, there have been two blinded randomized controlled

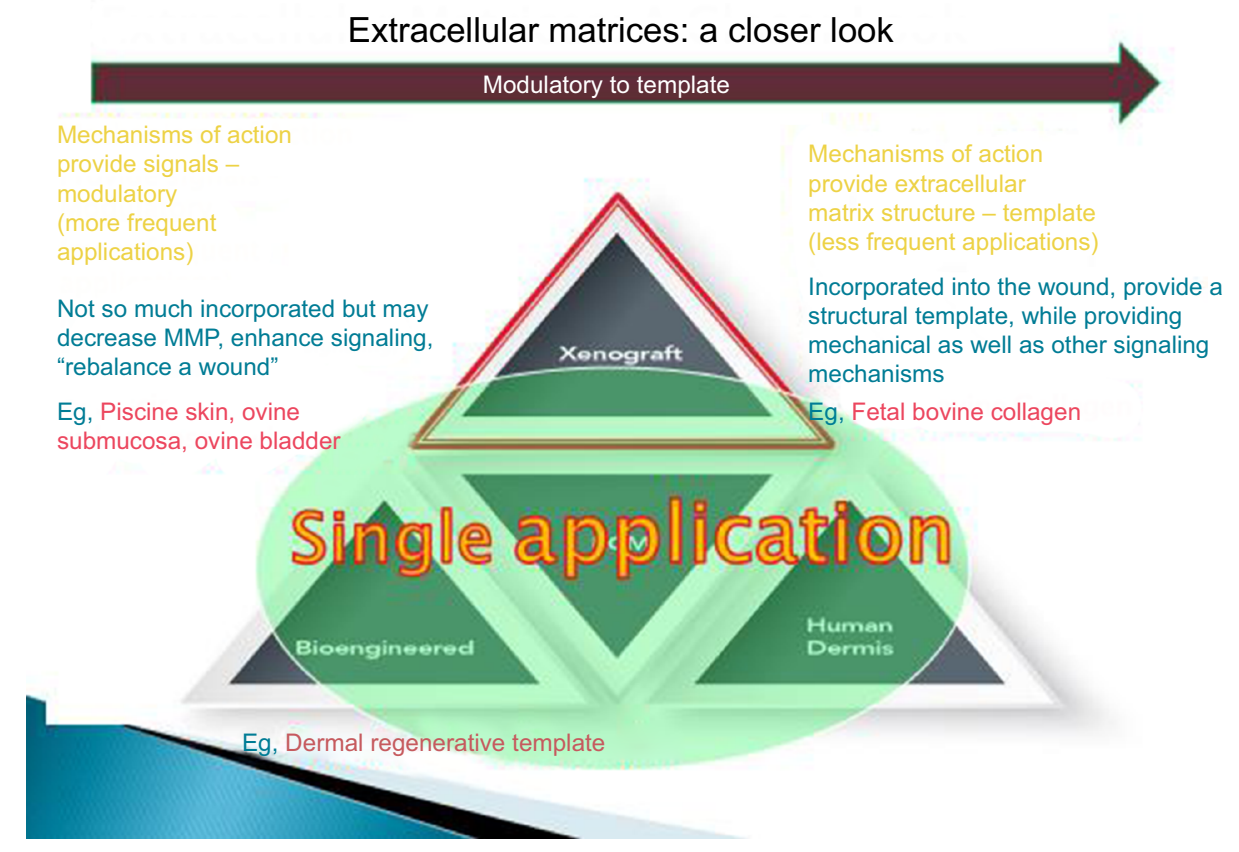

Figure I Spectrum of extracellular matrices. 
clinical trials showing that treatment of acute forearm wounds with AFS allows for significantly faster wound closure than porcine small intestine submucosa (SIS)-derived matrices ${ }^{12}$ and dehydrated human amnion/chorion membrane (dHACM). ${ }^{13}$

In 2014, the manufacturer of AFS needed to show the FDA that AFS was similar or superior to a presently commercially available ECM product in its ability to close wounds. As in almost all xenograft ECM product evaluations, they selected SIS as a predicate product. They then undertook a study with 81 healthy volunteers in which 162 acute $4 \mathrm{~mm}$ forearm punch model wounds were treated with SIS or AFS. There was significantly $(P=0.041)$ faster wound closure in the AFS group (Figure 2), and no autoimmune reaction, as evidenced by ELISA tests on rheumatoid factor, antinuclear antibodies, antinuclear cytoplasmic antibody, aetractable nuclear antibody, anti-double sided-DNA, anti- cyclic citrullinated peptide, and anticollagen I and II. ${ }^{12}$ These positive data allowed the entry of the AFS to the US market through the $510(\mathrm{k})$ pathway.

In late 2017 and early 2018, in response to the massive if somewhat unexplainable interest and use of amniotic/ chorionic products in the chronic wound marketplace, the makers of AFS sponsored another head-to-head acute wound closure study of dHACM vs AFS in the same $4 \mathrm{~mm}$ forearm punch model with 170 wounds. Eight-five wounds were treated with dHACM, and 85 were treated with AFS. Wounds treated with fish skin healed significantly faster over a 28-day period, with an HR of 2.37 (95\% CI: 1.75-3.21) at a $P$-value of 0.001 , compared to $\mathrm{dHACM}$ allograft-treated wounds (Figure 3). ${ }^{13}$

While the results of acute wound models are difficult to apply to the chronic wound patients, one can postulate that after complete surgical excision of a wound the local milieu may be similar. However, the patients are not similar. In both these studies, the patients were healthy volunteers in their third decade (on average) of life, which is usually not the case in the chronic wound population. Though, in both cases, the AFS promoted faster wound closure than comparative therapies, which would support the thought that at minimum it is a superior biologic dressing.

\section{Histologic features of Atlantic cod fish skin}

When studying the mechanism of action of an ECM, it may be "low hanging fruit" to simply look at the histologic properties of the acellular ECM and compare them to those of the native acellular ECM of human skin. While there may indeed be a sweet spot for this ECM anatomic profile, it is somewhat hard to support though many commercial companies do. In the case of AFS, this is no different. Histologic analysis demonstrates that after grafting, the AFS is incorporated into the damaged area and infiltrated by autologous cells that convert the graft into functional, living tissue while the graft slowly breaks down.

Investigation into the properties of the AFS that are important for tissue repair and regeneration has been undertaken employing microscopy-based techniques. Grossly, AFS

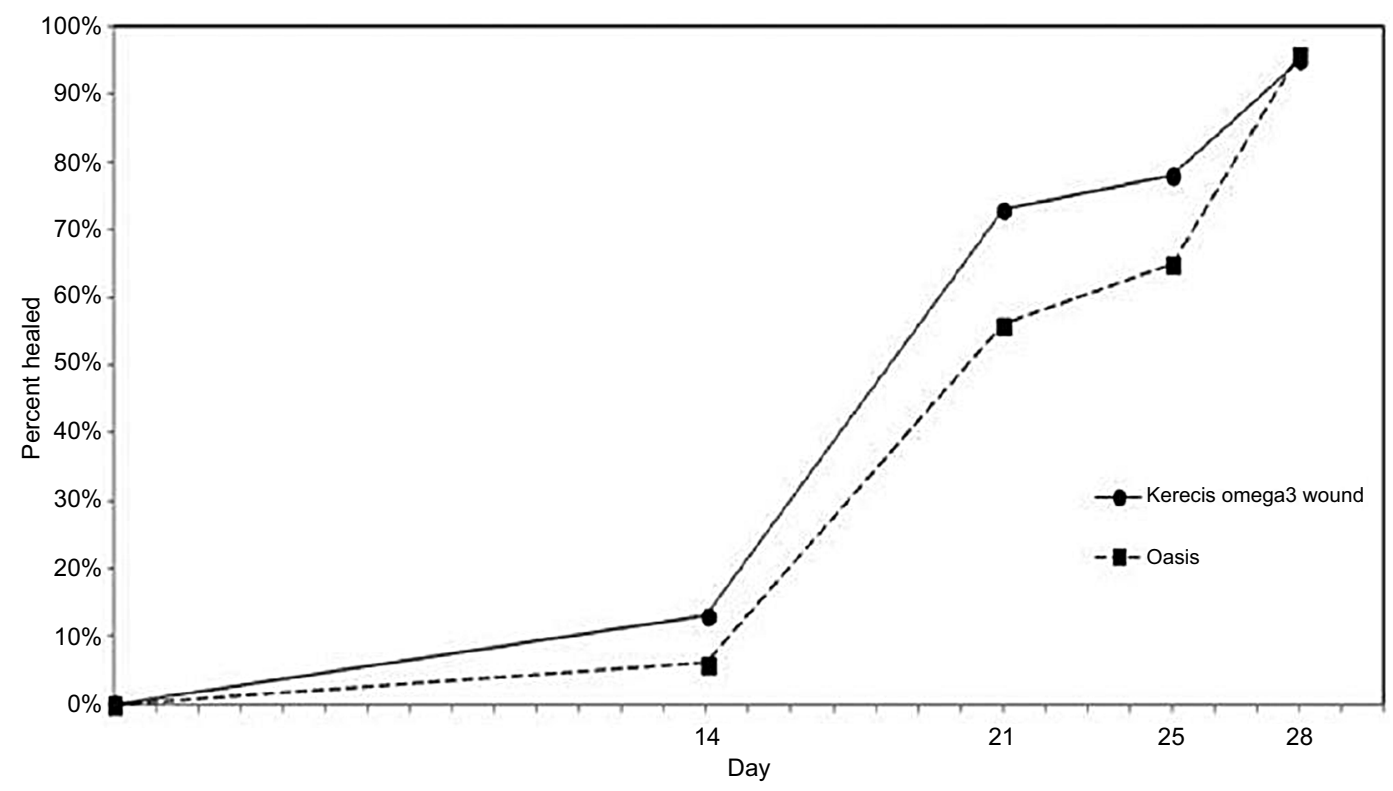

Figure 2 Increased acute wound closure rate seen with AFS over SIS in an acute wound care model.

Notes: Baldursson BT, Kjartansson H, Konrádsdóttir F, et al, Healing rate and autoimmune safety of full-thickness wounds treated with fish skin acellular dermal matrix versus porcine small-intestine submucosa: a noninferiority study. Int J Low Extrem Wounds (I4[I]) PP. 37-43, copyright @ 20I5 by (SAGE Publications). Reprinted by Permission of SAGE Publications, Inc. ${ }^{12}$

Abbreviations: AFS, acellular fish skin; SIS, small intestine submucosa. 


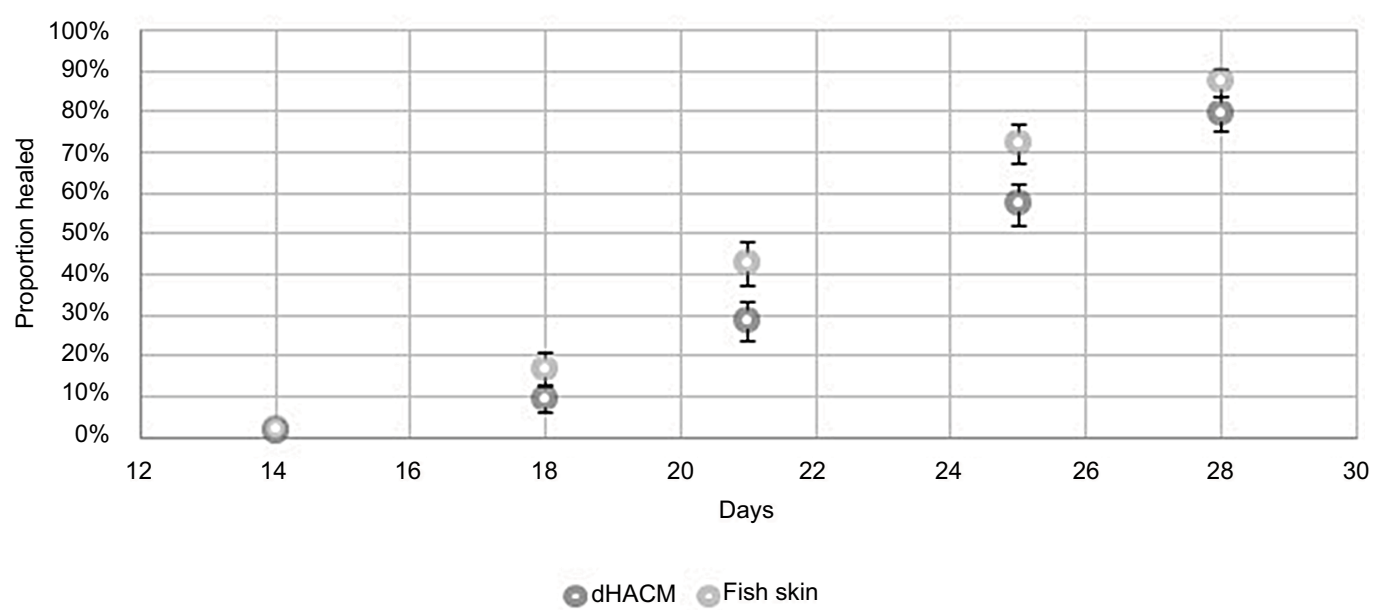

Figure 3 Increased acute wound closure rate seen with AFS over DHACM in an acute wound care model.

Notes: There is a particular difference in wound healing rate seen on days 2 I and 25. Reproduced from Lantis II JC, Petursdottir K, Baldursson B, Kirsner RS, DoubleBline WD. Prospective, randomized clinical trial on 170 acute wounds shows significantly faster healing rate with intact fish skin Compared to human amniotic membrane. Presentation at a conference. American Professional Wound Care Association (APWCA) sept 6-8, 2018 in Baltimore, MD, USA. ${ }^{13}$

Abbreviations: AFS, acellular fish skin; dHACM, dehydrated human amnion/chorion membrane.

has been compared to $\mathrm{AHACM}$ allograft, with respect to structure and ability to sustain fibroblast ingrowth in culture. In addition, the ability of the AFS to resist bacterial invasion has been studied.

\section{Porosity and thickness}

The porosity of the naturally occurring ECM was counted as the number of pores per $100 \mu \mathrm{m}$ of sample, and then software was implemented to measure the diameter of the pores. Pores with a diameter of $1 \mu \mathrm{m}$ or less were not imaged to calculate the diameter of pores under the scanning electron microscope. The microstructure of the biologic materials was evaluated, and it was found that the fish skin graft is highly porous compared to human amnion/chorion membrane. The fish skin contains 16.7 holes $(n=6)$ per $100 \mu \mathrm{m}$ on average, whereas the dHACM contains 1.7 holes $(n=6)$ per $100 \mu \mathrm{m}$ on average. The average diameter of the pores in the fish skin graft is $16.1 \mu \mathrm{m}(\mathrm{n}=5)$ and that of pores in the dHACM is $1.3 \mu \mathrm{m}(\mathrm{n}=3)$. The thickness of the dHACM is $20.1 \mu \mathrm{m}$ $(n=6)$ on average, and the thickness of the fish skin graft is $450 \mu \mathrm{m}(\mathrm{n}=6)$ on average. ${ }^{14}$

\section{Cell ingrowth assessment and quantification}

To assess cell ingrowth capability of the biologic materials, the scaffolds (AFS and dHACM) were seeded with cells. The cell cultures were then incubated. For further assessment, fluorescent staining was carried out with a hydrophobic barrier pen to surround the fixed tissue on the slides. ${ }^{14}$

Cell ingrowth was assayed and quantitated by counting fluorescently labeled cells within the biologic materials. Cells were considered ingrown when observed within the material. Cells were only counted when observed within the biologic materials, but not if they were on top of the material. Fibroblasts were seen to have infiltrated and remodeled the fish skin graft but did not interact with human amnion/ chorion membrane. AFS graft showed superior cell ingrowth when compared to human allograft. After evaluating the porosity of the biologic materials, it was hypothesized that the fish skin grafts are well suited to support cell ingrowth since the pore size is within the range of typical cell size. H\&E staining indicated that the fibroblasts remodeled the fish skin graft as they migrated and proliferated into the graft. The fibroblasts, however, formed a layer on top of dHACM allograft material and did not interact with the graft to the same extent. In this specific model, the AFS grafts showed significantly $(P<0.0001)$ more three-dimensional ingrowth of cells when compared to the AHACM. While none of these images alone could provide any specific evidence of how the material behaves, they, in general, support that the ECM is easily penetrated by precursor and circulating blood components and at a $100 \mu \mathrm{m}$ pore size, which appears to be in line with other ideal ECM structures. ${ }^{14}$

\section{The antimicrobial properties of fish skin}

It also appears from preclinical, small-mammal, and clinical data that the AFS grafts can withstand bacterial invasion for up to 48-72 hours. The original work chronologically started when Dr Baldursson was looking at the closure rate of a mouse burn model in mice treated with AFS. In this model, mice were burned for 30 seconds with brass blocks to create a third degree burn. The wounds were infected 5 minutes post-burn with $400-480 \times 10^{6}$ colony-forming units 
(cfu) of Proteus mirabilis strain ATCC51393. The animals in which AFS was placed on the burn wound before infection with $P$. mirabilis showed $100 \%$ survival rate and significantly $(P<0.05)$ more survival compared to control $(50 \%)$ mice and mice treated with collagen matrix product indicated for burns.

In parallel to this work, the barrier function of AFS was assessed. A dilute Staphylococcus aureus culture was prepared. Once fully incubated, colonies were counted on the plates and the number of cfu was counted in the initial suspension. Then, $200 \mu \mathrm{L}$ of precultured bacteria corresponding to 7,000 cfu was inoculated into one of the two chambers of a two-chamber unit in which a membrane made of fish skin to be tested was placed to cover the insert. The chambers were incubated at $37.0^{\circ} \mathrm{C}$ $\pm 1.0^{\circ} \mathrm{C}$. The AFS graft was tested by constraining the material between the two chambers and adding medium with bacteria on the other side and medium only in the second chamber. In this two-chamber assay, the fish skin graft preformed as a bacterial barrier for close to 60 hours compared to 5-45 hours observed for human amnion/chorion membrane products and several collagen matrix products. In addition to this, spiking the fish skin with more omega-3 fatty acids ( $>10 \%)$ enhanced its bacterial barrier function by roughly $80 \%$ (Figure 4 ). ${ }^{14}$

To follow this up, a very interesting observation was noted in a retrospective review of 54 nonhealing wounds which were treated with AFS for a period of 4 weeks and

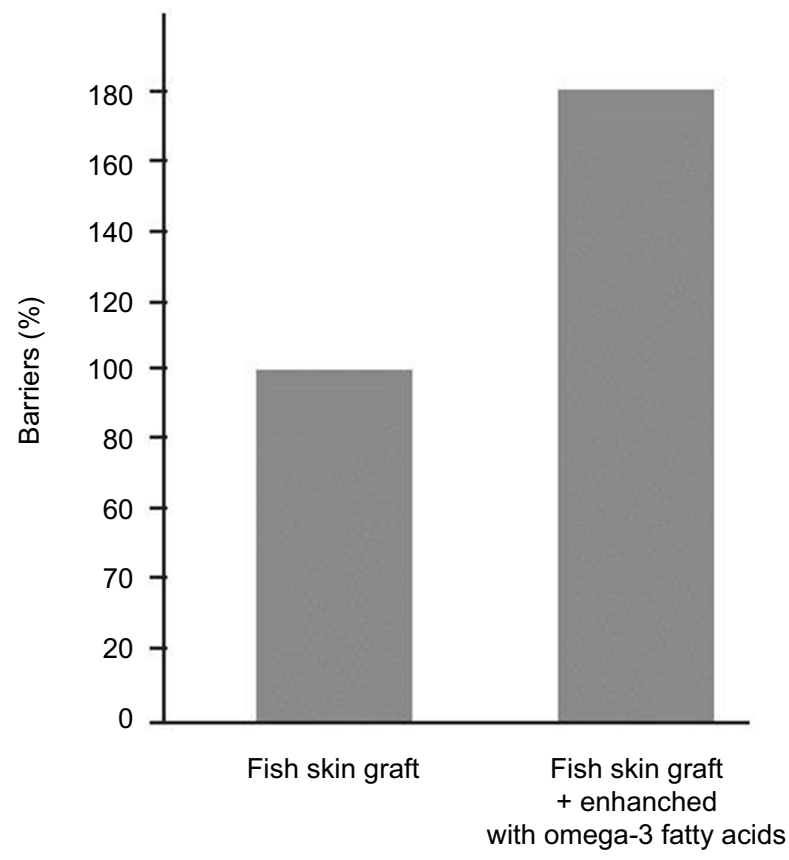

Figure 4 Efficacy of AFS as a bacterial barrier and the increased efficacy seen with the addition of greater omega-3 fatty acids.

Notes: Magnusson S, Baldursson BT, Kjartansson H, Rolfsson O, Sigurjonsson GF, Regenerative and antibacterial properties of acellular fish skin grafts and human Amnion/Chorion membrane: implications for tissue preservation in combat casualty care, Mil Med, 2017, I82, SI, 383-388, by permission of Oxford University Press. ${ }^{14}$ Abbreviation: AFS, acellular fish skin. two applications on average. Improvement was defined as a $>20 \%$ reduction of wound area. Data were extracted from the patient records database at the Landspitali University Hospital in Reykjavik, Iceland, which was approved by the National Bioethics Committee of Iceland (VSN-15-137). Antibiotics therapy was not a predetermined end point since this was a retrospective study. However, it was noted that after treatment with AFS there was a 38\% reduction in antibiotics use (Figure 5). Overall, $87 \%$ of nonhealing wounds treated with fish skin grafts either improved or healed after 4 weeks of treatment. Interestingly, while it was only a retrospective observational study, no wound became worse in the course of the 4-week treatment with the AFS. ${ }^{15}$ These benchtop, small-animal data, supported by clinical observations, create the beginning of a story that supports the possibility that this naturally occurring ECM may have intrinsic antimicrobial properties, which may be secondary to the omega-3 fatty acids that it naturally contains.

\section{Clinical experience with fish skin}

If one looks at the peer-reviewed literature, other than the 166 patients in the two acute wound randomized controlled trials, there are only 59 patients treated with AFS (Table 1). There are two case series that are referred to in the US on specific wound types, including one by our group evaluating "hard-to-heal" venous leg ulcers, and as part of a very large cohort (yet to be published), and a small subset analysis of diabetic foot ulcers treated in Dr Chris Winters podiatric practice in Indiana, USA.

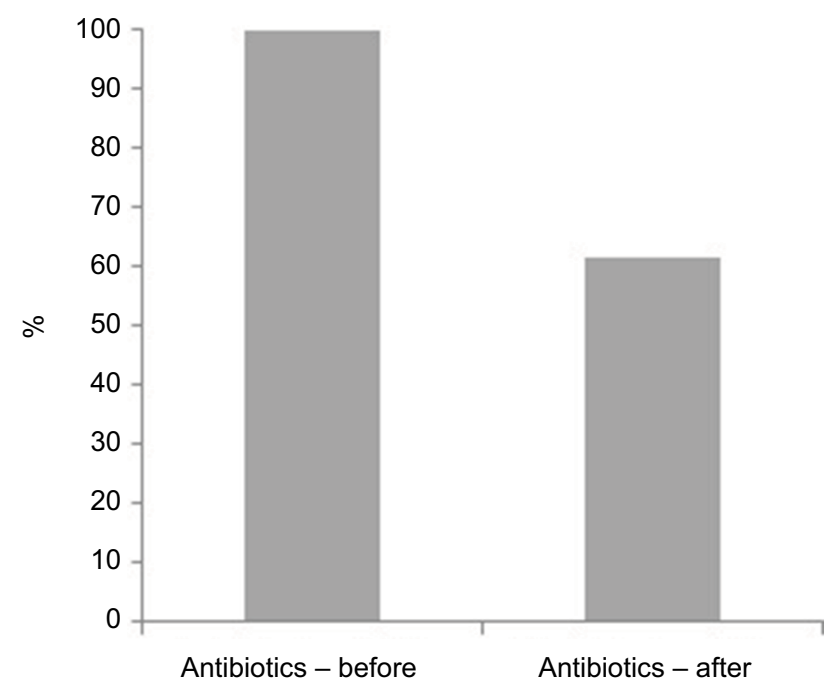

Figure 5 Clinical use of antibiotics before and after the application of AFS in a cohort of chronic wound patients.

Note: Reproduced from Lantis II J, Baldursson B, Magnusson S, Kjartansson SG. Acellular fish skin graft for surgical, trauma, venous and arterial and diabetic wounds: a retrospective clinical study. Paper presented at: 17th Congress of the Asian Society for Vascular Surgery; October 20-23, 2016; Singapore. ${ }^{15}$

Abbreviation: AFS, acellular fish skin. 


\begin{tabular}{|c|c|c|c|c|c|}
\hline & 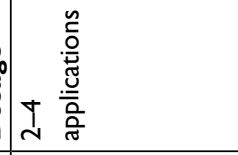 & 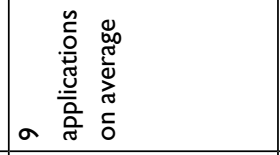 & 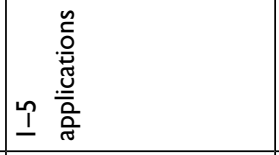 & 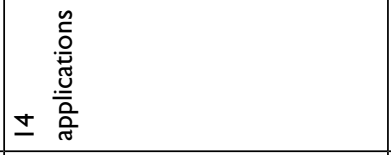 & 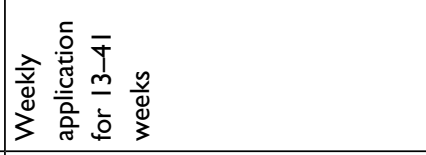 \\
\hline & 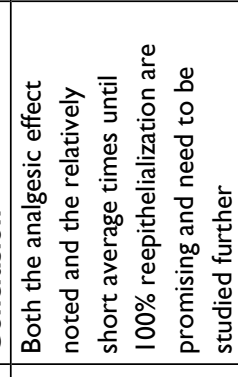 & 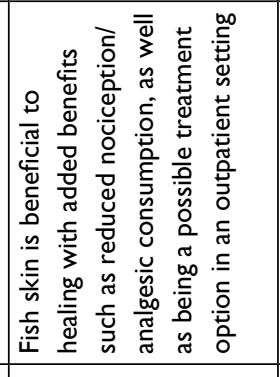 & 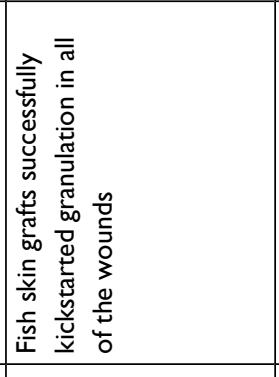 & 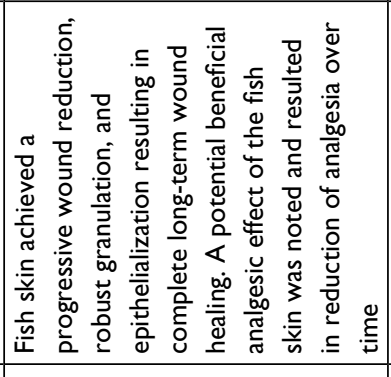 & 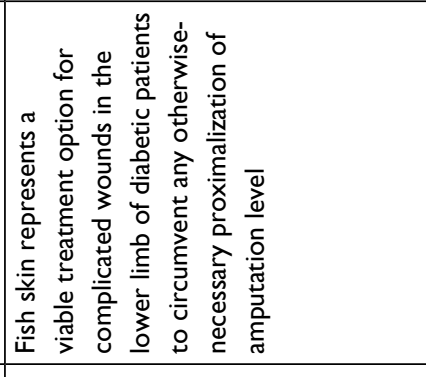 \\
\hline 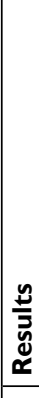 & 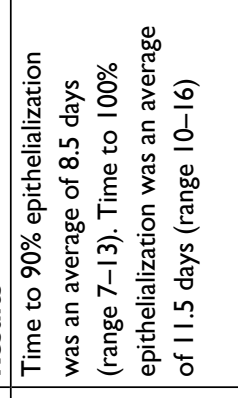 & 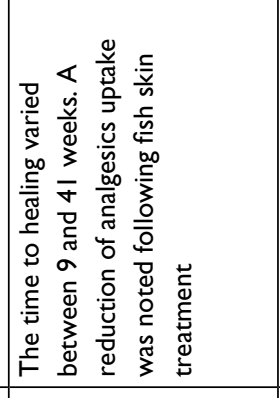 & 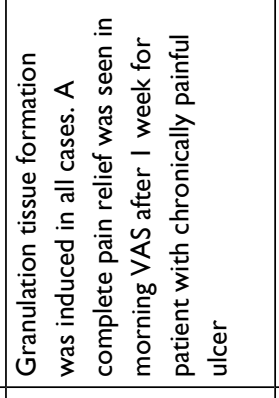 & 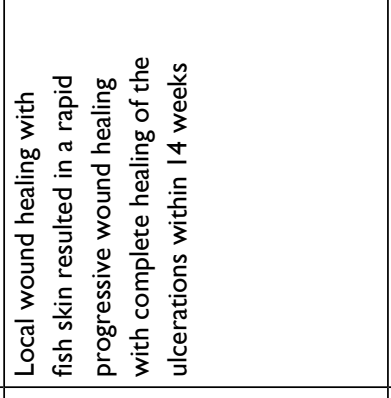 & 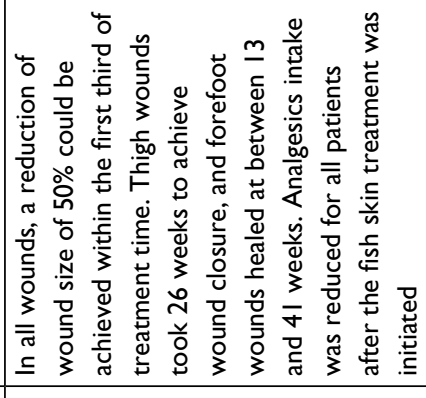 \\
\hline & 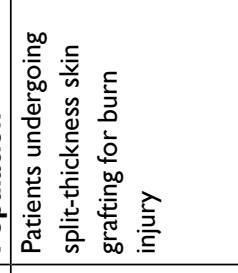 & 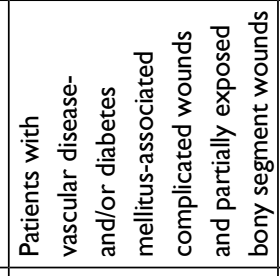 & 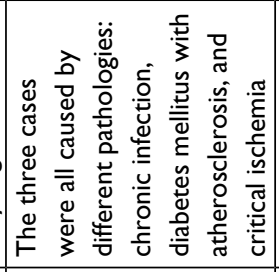 & 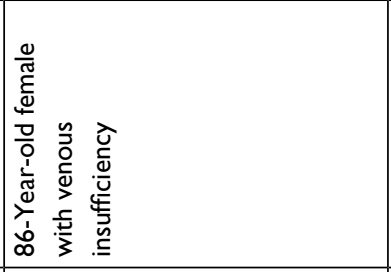 & 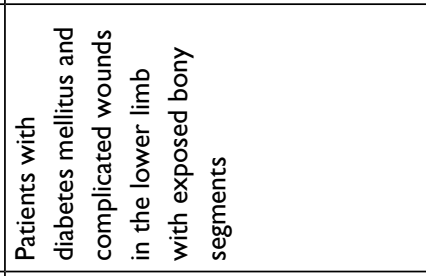 \\
\hline$z$ & 으 & $\ddot{\sim}$ & $\mathrm{m}$ & - & in \\
\hline 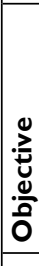 & 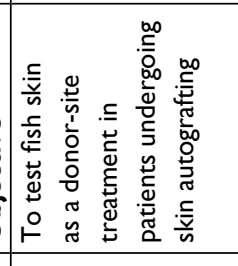 & 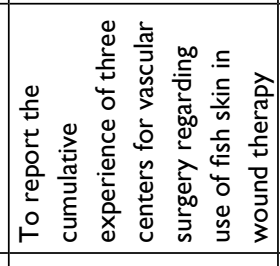 & 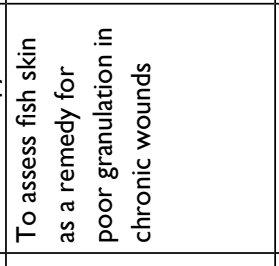 & 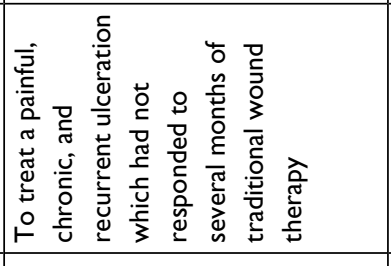 & 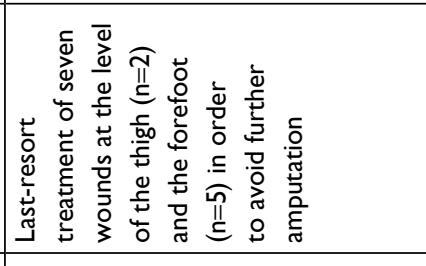 \\
\hline 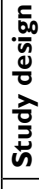 & 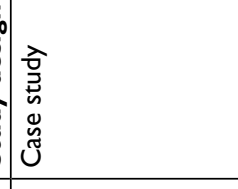 & 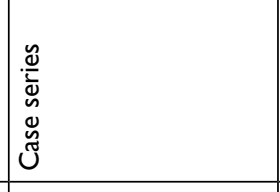 & \begin{tabular}{|l}
$\mathscr{\mathscr { \omega }}$ \\
$\overline{\bar{\nu}}$ \\
$\tilde{\omega}$ \\
$\tilde{y}$ \\
$\tilde{J}$ \\
\end{tabular} & \begin{tabular}{|l}
$\hat{\lambda}$ \\
$\vec{Z}$ \\
$\hat{U}$ \\
0
\end{tabular} & 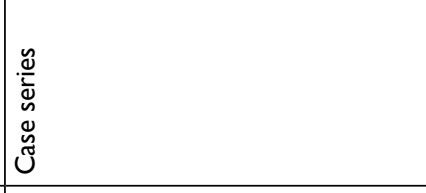 \\
\hline 异 & 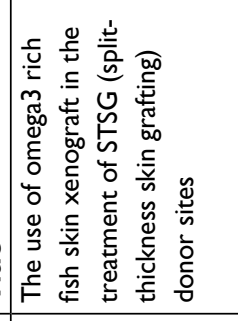 & 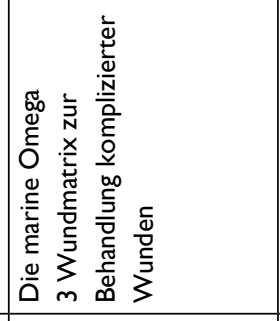 & 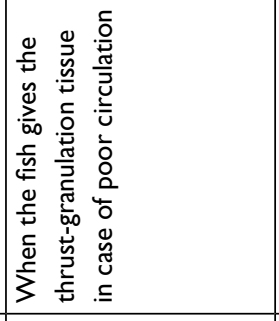 & 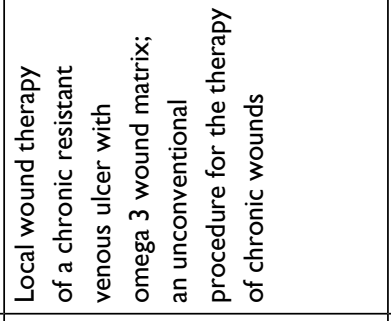 & 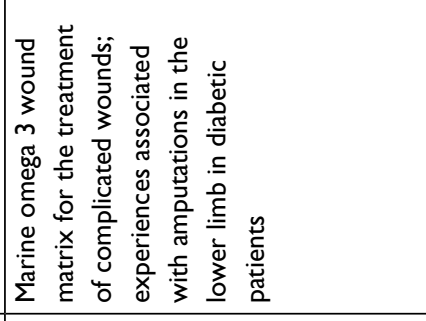 \\
\hline 䆛 & 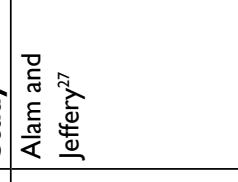 & 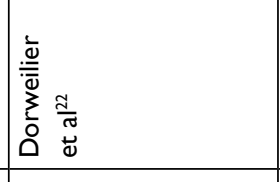 & 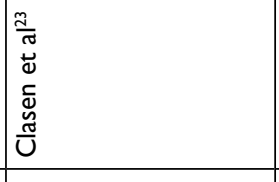 & 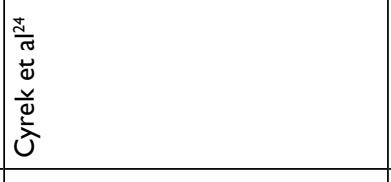 & 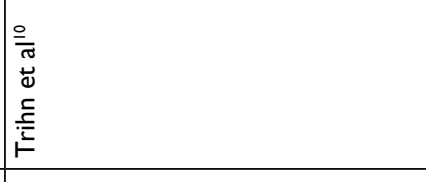 \\
\hline & 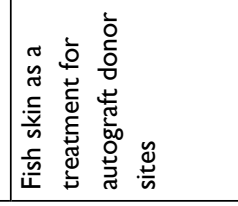 & 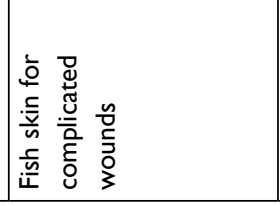 & 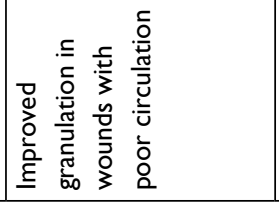 & 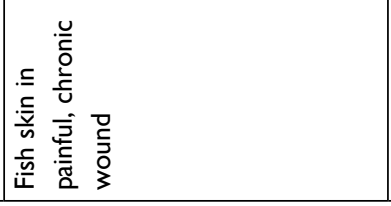 & 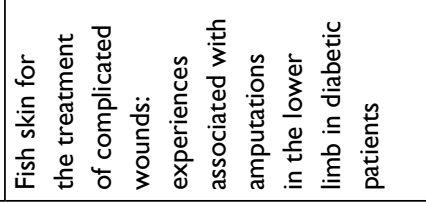 \\
\hline
\end{tabular}




\begin{tabular}{|c|c|c|c|c|}
\hline 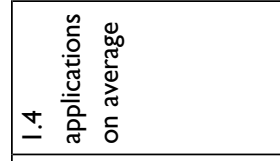 & 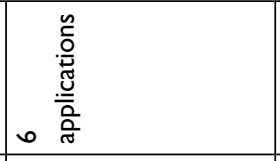 & 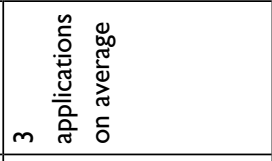 & 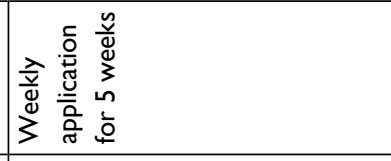 & 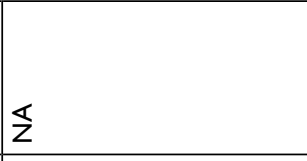 \\
\hline 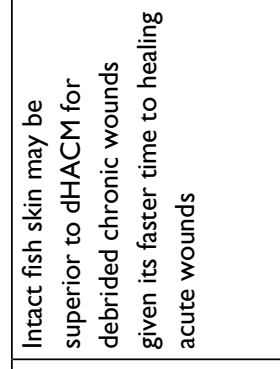 & 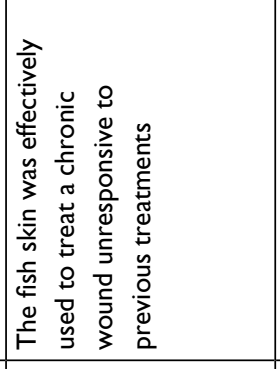 & 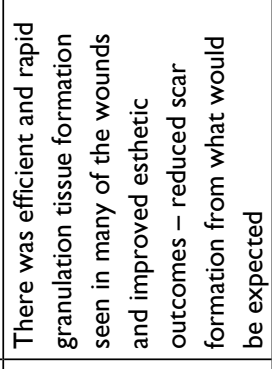 & 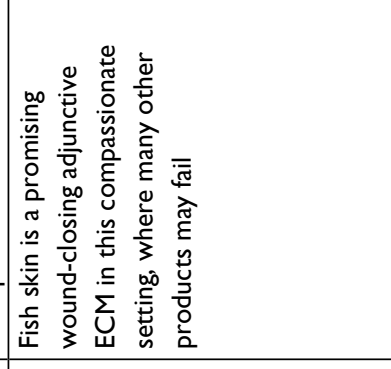 & 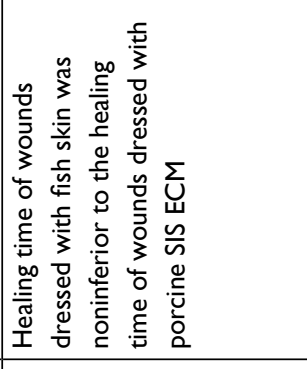 \\
\hline 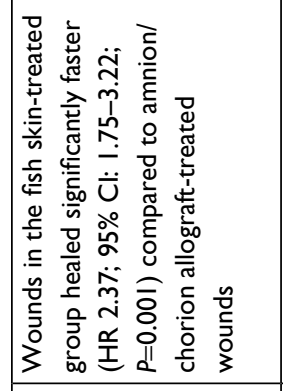 & 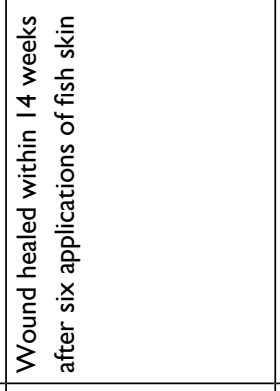 & 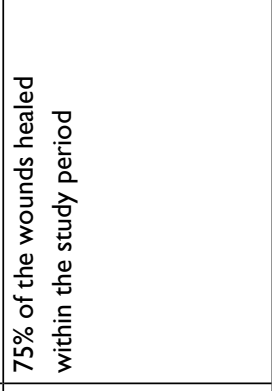 & 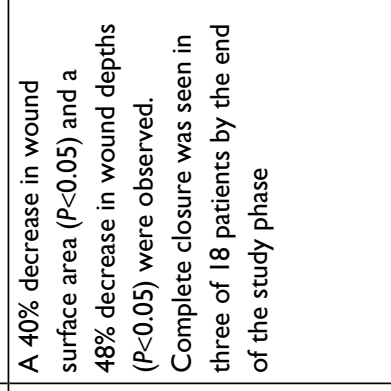 & 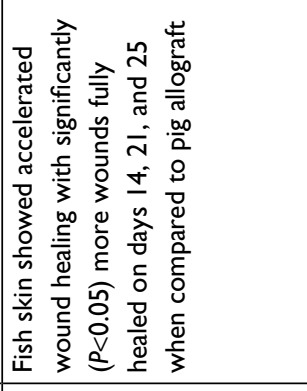 \\
\hline & 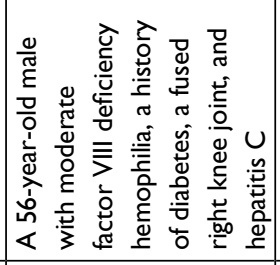 & 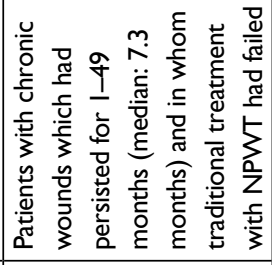 & 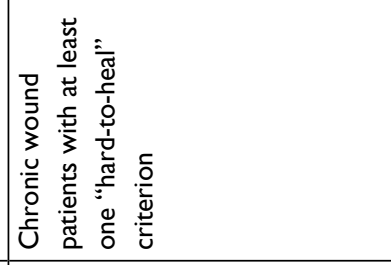 & 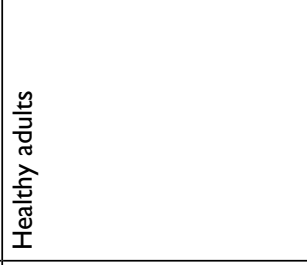 \\
\hline$\stackrel{\infty}{\infty}$ & - & $\underline{0}$ & $\underline{\infty}$ & $\bar{\infty}$ \\
\hline 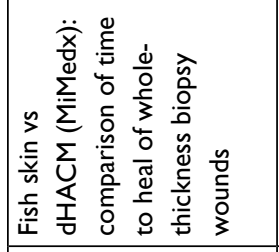 & 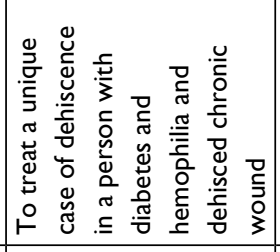 & 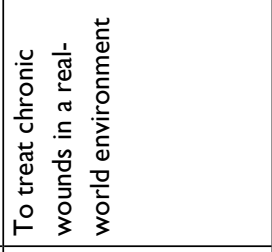 & 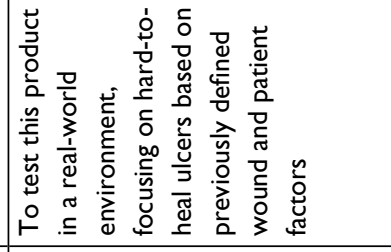 & 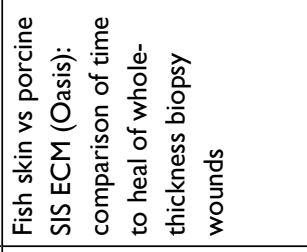 \\
\hline 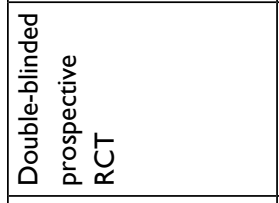 & 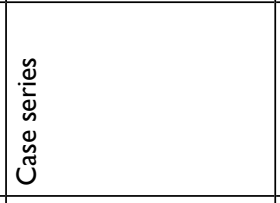 & 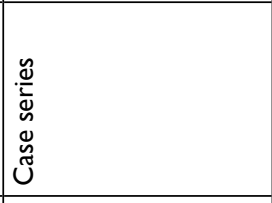 & 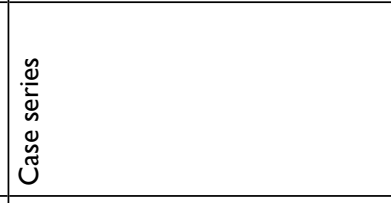 & 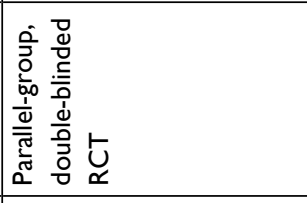 \\
\hline 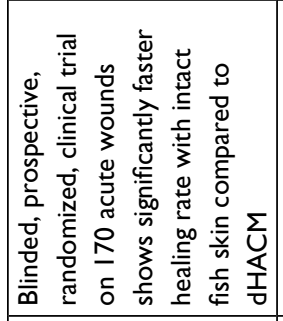 & 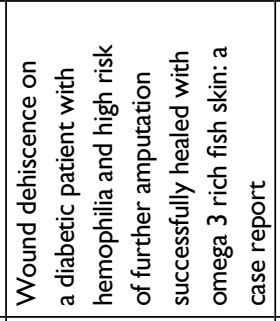 & 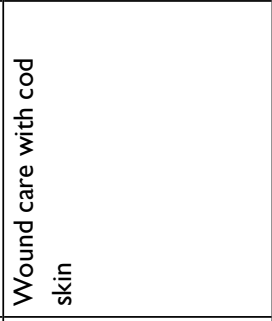 & 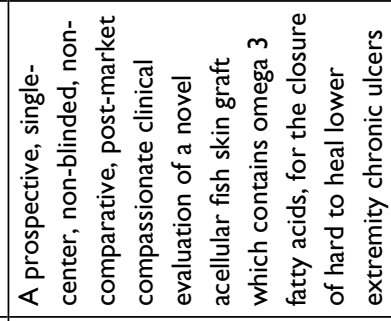 & 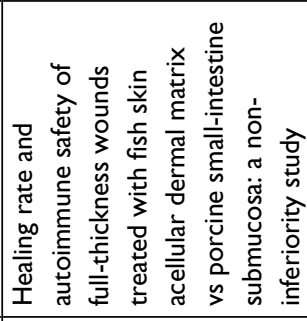 \\
\hline 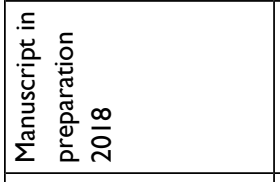 & 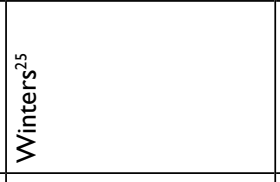 & 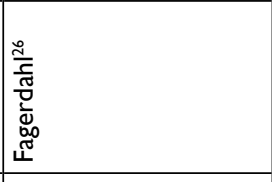 & 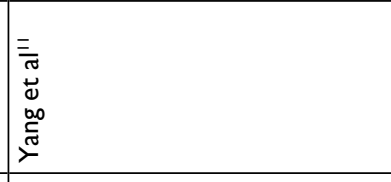 & 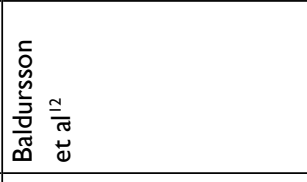 \\
\hline 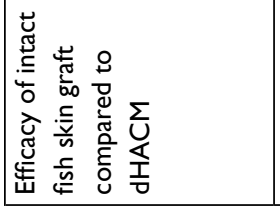 & 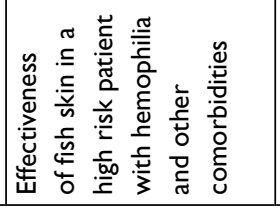 & 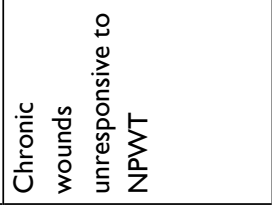 & 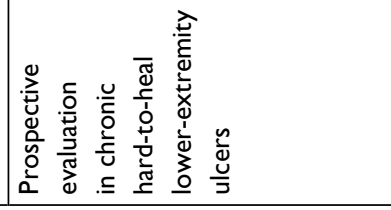 & 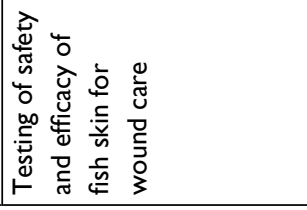 \\
\hline
\end{tabular}


We prospectively evaluated the percentage of wound closure area from baseline after five weekly AFS applications in 18 patients with at least one "hard-to-heal" criterion (area $>10 \mathrm{~cm}^{2}$ or duration of wound $>52$ weeks). The AFS was placed weekly for 5 weeks, followed by 3 weeks of standard care; secondary wound dressings were applied per the underlying etiology. Wound area reduction and signs of infection were noted and reviewed weekly. There was a $40 \%$ decrease in wound surface area with five weekly applications $(P<0.05)$. In addition, the patients reported a notable reduction in pain and drainage. Interestingly, the wound area reduction ceased when the product application was halted (Figure 6). ${ }^{11}$

Dr Chris Winters in the US used data from his practice and created a very interesting cost simulation model in which data from 27 diabetic wounds treated with AFS were inserted into the prognostic model, and compared with the actual outcome of the treatment. The prognostic model was built on Dr Margolis' widely publicized work, in which a model was generated using data from 27,630 patients with diabetic foot ulcers. The model predicts the likelihood of a wound not healing after 20 weeks based on some of the following parameters being met: size $>2 \mathrm{~cm}^{2}$, previous duration of wound $>2$ months, and Wagner ulcer grade $\geq 3$ (Table 2 ). ${ }^{16}$ The model was then used to check the predicted healing of the 27 patients vs the actual healing when these patients were treated with AFS. At 20 weeks, according to the predictive model, in 11 of the 27 patients, the wounds should have been closed with standard care, but, with AFS treatment, 24 patients had healed. ${ }^{17}$

Various case series and case reports have been published, including, but not limited to, those focusing on traumatic wounds, skin graft donor sites, and diabetic foot wounds

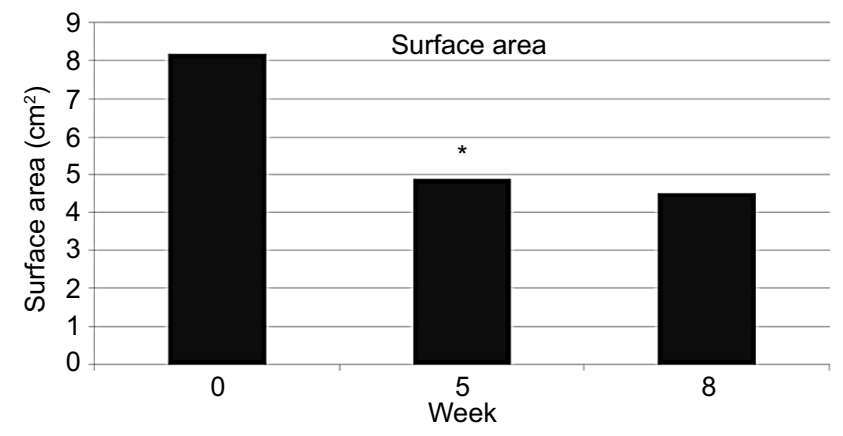

Figure 6 Mean wound surface area as noted during the 5-week AFS treatment and 3-week follow-up of venous leg ulcers."

Notes: *indicates statistic significance. Reproduced with permission from Yang CK, Polanco TO, Lantis JC. A prospective, postmarket, compassionate clinical evaluation of a novel acellular fish-skin graft which contains omega-3 fatty acids for the closure of hard-to-heal lower extremity chronic ulcers. Wounds. 2016;28(4): II2-1I8. Copyright 2019. Wounds."

Abbreviation: AFS, acellular fish skin.
Table 2 Likelihood of healing by prognostic factors

\begin{tabular}{|l|l|l|l|}
\hline $\begin{array}{l}\text { Size } \mathbf{>} \mathbf{2} \\
\mathbf{c m}^{\mathbf{2}}\end{array}$ & $\begin{array}{l}\text { Ulcer } \\
\text { grade } \mathbf{2 3}\end{array}$ & $\begin{array}{l}\text { Duration } \mathbf{2} \\
\text { months }\end{array}$ & $\begin{array}{l}\text { Modeled expected } \\
\text { likelihood of healing }\end{array}$ \\
\hline & & & 0.66 \\
\hline $\mathrm{x}$ & & & 0.52 \\
\hline & & $\mathrm{x}$ & 0.53 \\
\hline & $\mathrm{x}$ & & 0.47 \\
\hline $\mathrm{x}$ & & $\mathrm{x}$ & 0.33 \\
\hline $\mathrm{x}$ & $\mathrm{x}$ & & 0.31 \\
\hline & $\mathrm{x}$ & $\mathrm{x}$ & 0.38 \\
\hline $\mathrm{x}$ & $\mathrm{x}$ & $\mathrm{x}$ & 0.22 \\
\hline
\end{tabular}

Notes: The table shows the likelihood that a wound with a given prognostic factor or combination of prognostic factors will heal after 20 weeks. $X$ denotes the presence of one of the prognostic factors.

with exposed bone or tendon (Table 1). At present, clearly more prospective evaluation of clinical series and controlled studies is necessary to support the application timing and to generate information on the expected outcomes. There needs to be a much more aggressive attempt by practitioners and the makers of the product to develop a registry of patients by which one can better understand the application schedule and expected outcomes of the product.

Based on the authors' personal use of the product and the proctoring of other physicians, the application of this product requires a wound bed that can range from a surgically prepped one (application in the operating room $[\mathrm{OR}])$ to the one that fundamentally needs a biologic dressing, such as a venous leg ulcer. It appears that this modulatory ECM needs to be reapplied at 4-7 days after its first application, and at present, weekly application is the standard. However, an application interval window of 2 weeks certainly seems to occur frequently in practice and in our experience. The ideal "dosing frequency" per wound type has yet to be defined. However, no other CTP has documented appropriate dosing guidelines to date (with the possible exception of the dermal (re)generative templates), most likely due to an eye toward sales, and not clinical efficacy (Figure 7).

\section{Translational research and the omega-3 fatty acids question}

The primary question that exists around AFS is whether the intrinsic omega-3 fatty acids in the product allow for any special properties for this CTP. Answering the primary question requires answers to a couple of other questions: the first, does AFS contain relevant amounts of omega-3 fatty acids that matter in vitro, and the second, does this amount of omega-3 fatty acids make a difference in vivo. The AFS 


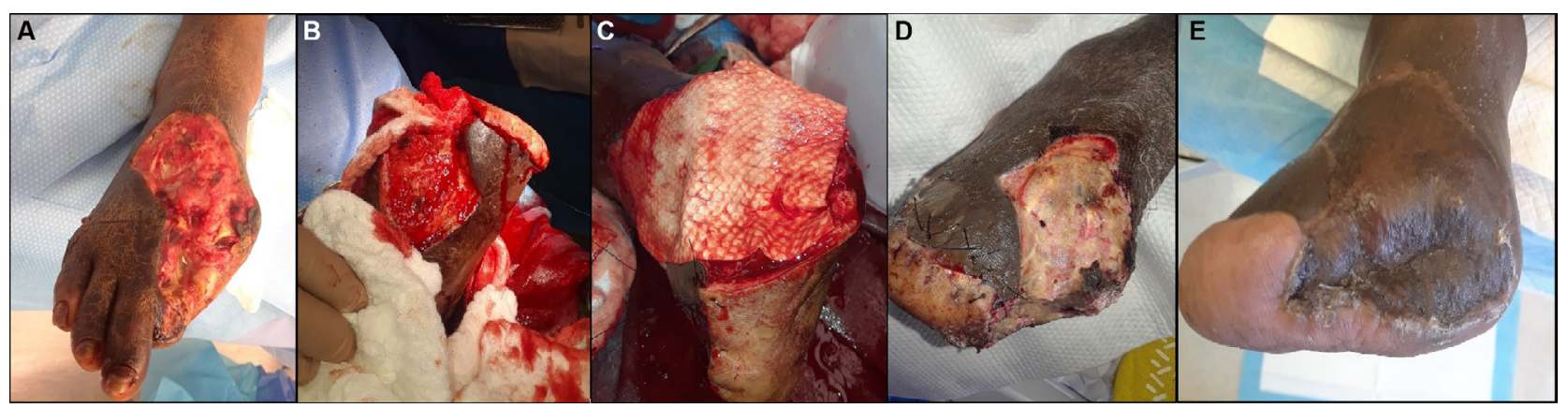

Figure 7 (A) Post-debrided foot with exposed bone. (B) Completion of transmetatarsal amputation. (C) Placement of AFS. (D) Post-op day 4 with no negative-pressure wound therapy. (E) Three weeks after grafting.

Abbreviation: AFS, acellular fish skin.

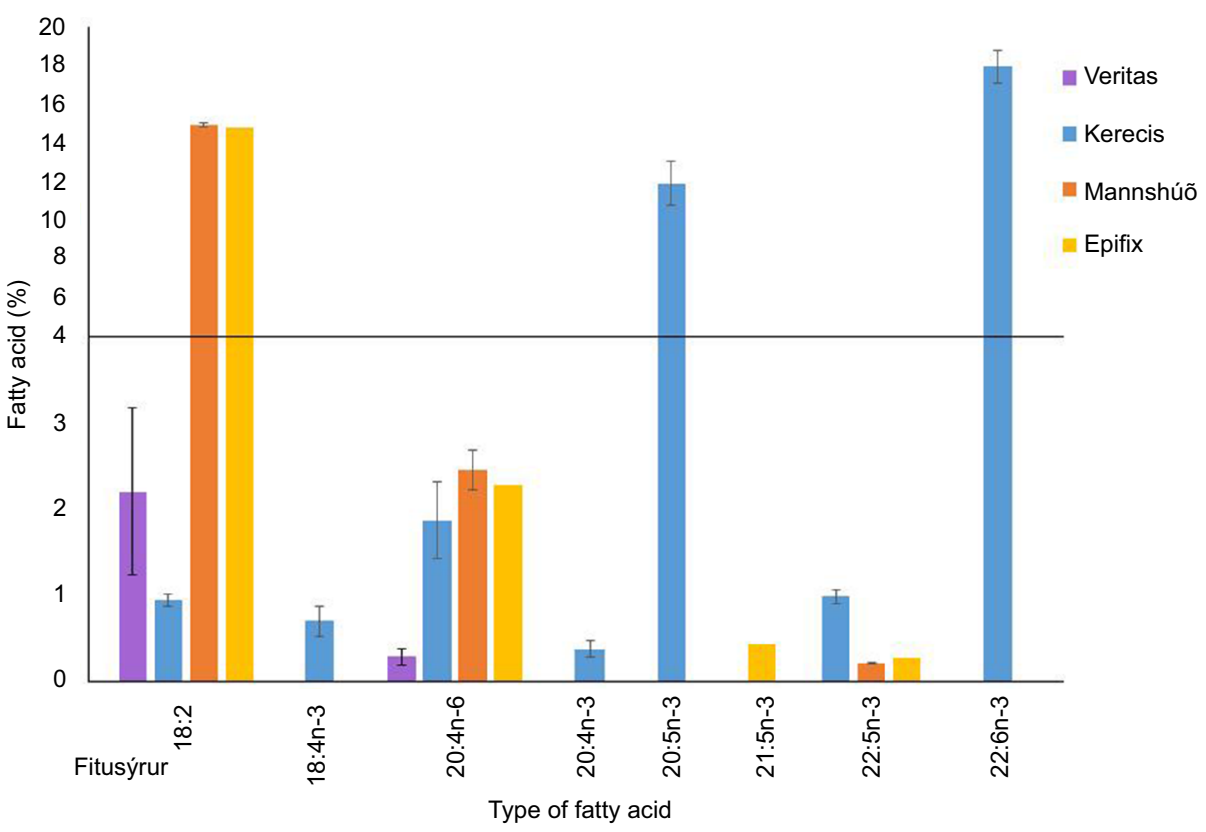

Figure 8 Levels of omega- 3 and omega- 6 fatty acids in various products with $y$-axis being the percent of fatty acid and $x$-axis being the type of fatty acid.

Note: Reproduced from Lantis J, Magnusson S, Baldursson B, Kjartansson H, Rolfsson O, Sigurjonsson G. Fish skin omega-3 PUFAs induce cell migration and transcription of ALOX 15, a specialized pro-resolving mediator forming lipoxygenase. Paper presented at: SAWC Fall; October 20-22, 20I7; Las Vegas, NV. ${ }^{18}$

contains omega-3 fatty acids naturally distributed in the skin scaffolding, specifically those of docosahexaenoic acid and eicosapentaenoic acid types, while being low in omega-6 fatty acids (Figure 8 ). ${ }^{18}$

In an attempt to further assay the effect of omega-3 fatty acids on wound closure, an in vitro keratinocyte wound model was created in a study. The constituent fatty acids from the AFS were delivered to the keratinocyte injury model, while the control received no fatty acids. The group treated with the lipid extract closed $20 \%$ faster with the lipid extract increasing the migration of cells to the wound bed. The mechanism of action by which this was promoted may include omega-3 fatty acids-induced activation of specialized pro-resolvin pathways, which lead to reduction of prostaglandins and less inflammation, the same downstream effects observed with NSAIDs. ${ }^{18}$

Interestingly, this NSAID effect has been seen by our group clinically with significant reduction in pain in patients with venous leg ulcer $(n=18)$, as well as in 23 patients with vascular disease and diabetes mellitus who had foot wounds. The clinical significance has been great enough to support an application to the US Department of Defense (DOD) for the use of AFS to help reduce narcotic dependence in patients with severe wound pain. AFS may also have a role in atypical wounds such as vasculitis. To date, there is really only one CTP, a dermal regenerative template, with a documented role in atypical wounds. ${ }^{19}$ However, the prospective trial proposed to the DOD 
includes patients with vasculitis, which if enrolled will be the first CTP trial to actively recruit vasculitic patients prospectively.

\section{Using fish skin in burns}

The burn market remains one of the targets for skin substitutes, despite the fact that the number of severely burned individuals in most of the world is decreasing due to public health initiatives. ${ }^{20}$ In addition to this, an immediate posttrauma/modern battlefield dressing is attractive if it has intrinsic hemostatic and antimicrobial properties. Also, an agent that can enhance the speed of closure gains attention, particularly a dressing that can enhance the quality of wound bed and reduce the time to closure.

Recently, the US Army Institute of Surgical Research Combat Trauma and Burn Injuries Research Group, under the direction of Randolph Stone II, $\mathrm{PhD}$, have reported on their assessment of AFS in an established porcine burn model. The objective of their project was to evaluate decellularized fish skin graft on deep partial-thickness (DPT) and full-thickness (FT) burn wounds in a preclinical porcine model. More specifically, the project aimed to evaluate fish skin graft as an acellular dermal matrix for its ability to integrate and improve healing of DPT burn wounds, to assess the use of fish skin graft as a temporary dressing prior to grafting, and to look at its ability to improve healing of highly meshed autografts on FT burn wounds. The animals were wounded and treated as shown in Table 3. There were six animals in each group, and 12 wounds were created per animal. Wound closure, wound perfusion, hydration, and contracture were assayed. ${ }^{21}$

Table 3 Porcine burn model treatment groups

\begin{tabular}{|l|l|l|l|l|}
\hline $\begin{array}{l}\text { Group } \\
\text { number }\end{array}$ & $\begin{array}{l}\text { Burn depth } \\
\text { (day I) }\end{array}$ & $\begin{array}{l}\text { Primary } \\
\text { treatment } \\
\text { after } \\
\text { excision of } \\
\text { dead tissue } \\
\text { (day 0) }\end{array}$ & $\begin{array}{l}\text { mSTSG } \\
\text { application } \\
\text { (day 7) } \\
\text { (meshing } \\
\text { ratio) }\end{array}$ & $\begin{array}{l}\text { Second } \\
\text { application } \\
\text { of Kerecis } \\
\text { (day 7) }\end{array}$ \\
\hline I & Full thickness & Kerecis & Yes (I.5:I) & No \\
\hline 2 & Full thickness & Kerecis & Yes (3:I) & Yes \\
\hline 3 & Full thickness & Cadaver skin & Yes & No \\
\hline 4 & $\begin{array}{l}\text { Deep partial } \\
\text { thickness }\end{array}$ & PriMatrix & No & No \\
\hline 5 & $\begin{array}{l}\text { Deep partial } \\
\text { thickness }\end{array}$ & Kerecis & No & Yes \\
\hline
\end{tabular}

Abbreviation: mSTSG, meshed split thickness skin graft.
Their findings supported that AFS was easy to apply to wounds and not conducive to bacterial colonization. AFS allowed faster reepithelialization of DPT burn wounds when compared to fetal bovine dermis. The quicker reepithelialization did not result in higher contraction rates as were seen in the no-treatment group. The tissue hydration levels correlated with the reepithelialization, and there was a quicker return to normal skin levels with the AFS treatment. Also, maybe most importantly, AFS integrated into the wound bed quickly, thus potentially allowing the skin graft to close the wound sooner. Overall, these data are very supportive of progressing to a clinical trial in human burns. In the senior author's practice, it is a preclinical evidence of the AFS supporting a rich wound bed that is suitable for skin grafting at an earlier time period (Figure 9). ${ }^{21}$

\section{Next steps in research}

In the near future, we hope to be able to see in the peerreviewed literature a large cohort of diabetic foot ulcers and their treatment paradigm along with the above analysis/ comparison of AFS to multiple other CTPs in a known military burn animal model. In conjunction, publication and elucidation of a comprehensive analysis of the content of AFS (collagen, proteoglycan, glycosaminoglycan components), development of a more extensive "bank" of tissue biopsies of human wounds at 1 week and 1 month post-implantation with histology, and a trial of dosing strategy such as two times the first week, then one time a week, and finally once every other week are needed. It would also be very interesting to see how AFS behaves under flaps and possibly in support of tendon repairs.

However, the real elephant in the room is the need to better elucidate the possible unique properties of the intrinsic omega-3 fatty acids. There appears to be some signal that they enhance the bacterial barrier function of the product and possibly aid in downregulating pain. Wound assays that look for their levels in the wound at post-op days 4 and 7 would be interesting, especially if tied to assays of wound inflammatory markers.

\section{Conclusion}

We are just starting to understand AFS, an ECM which is new to the market. The unique omega-3 fatty acid content in addition to the relatively biologically ideal three-dimensional ECM structure makes it an intriguing solution to the clinical needs of the chronic wound-treating physicians. So far clinically, it has appeared to act as a very efficient modulatory 
A

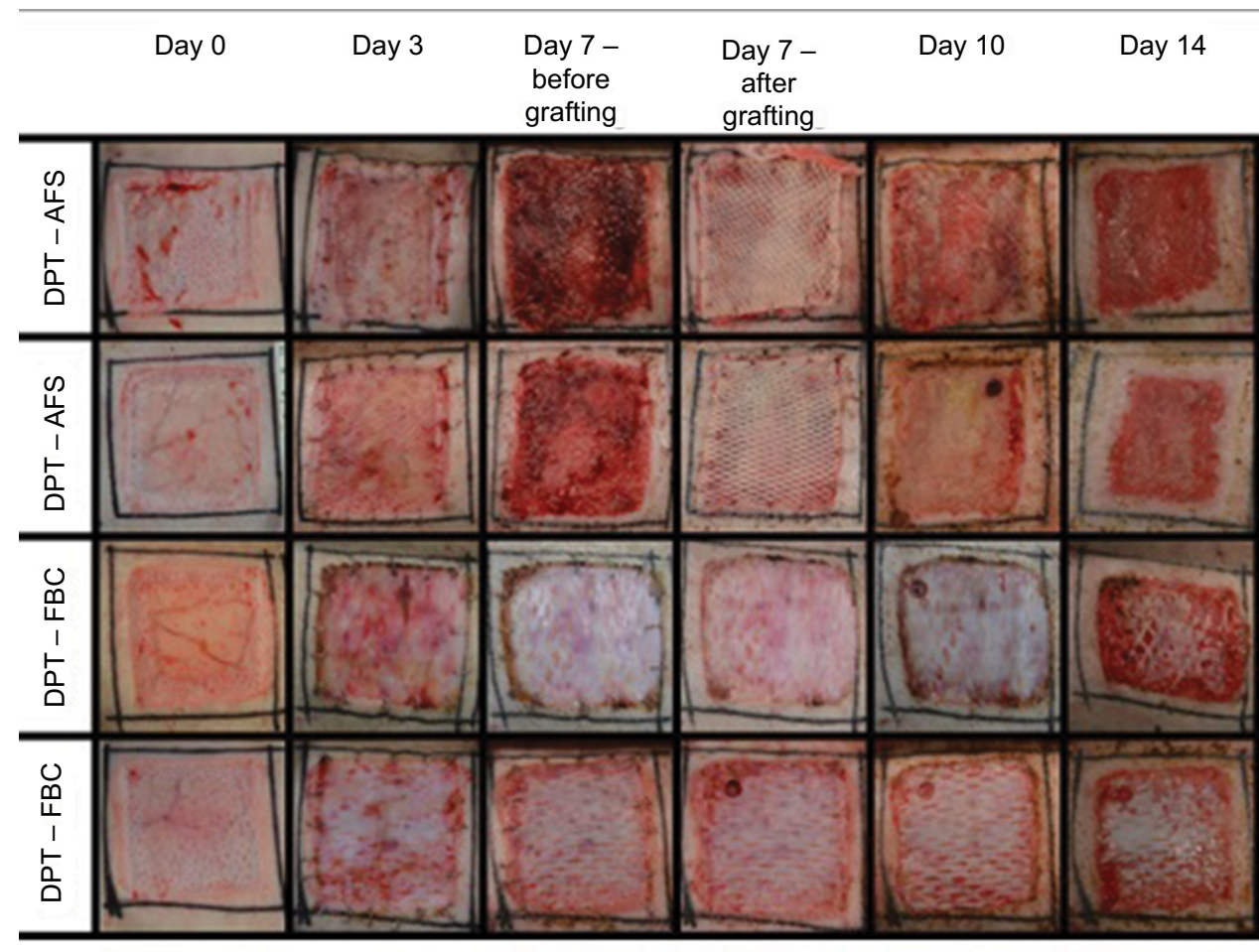
B
Day 21
Day 28
Day 35
Day 45
Day 60

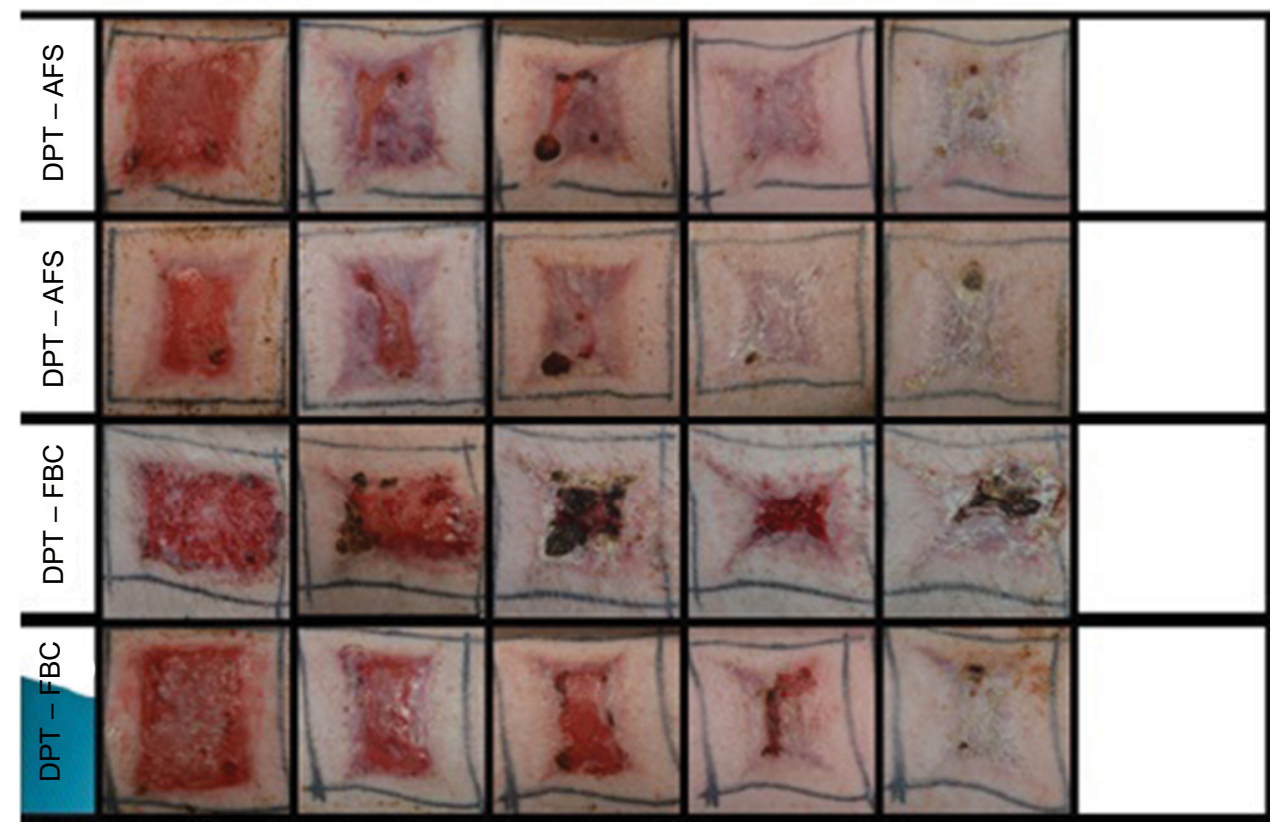

Figure 9 Progression of porcine wound closure when treated with AFS with and without skin grafting. Abbreviations: AFS, acellular fish skin; DPT, deep partial thickness; FBC, fetal bovine collagen.

ECM that is resistant to bacteria, and the anti-inflammatory omega-3 fatty acids content makes it very attractive for their potential added pain reduction. The fact that in some cases it can be skin grafted early at 7 days is also a benefit.
At present, it can be used immediately after burn excision or wide soft tissue resection in the OR, in negative-pressure wound therapy, and also in the clinic after wound debridement with appropriate supportive dressing. 


\section{Disclosure}

John C Lantis II is a paid consultant for Kerecis. Munir Patel reports no conflicts of interest in this work.

\section{References}

1. Falanga V, Sabolinski ML. A bilayered living skin construct (Apligraf ${ }^{\circledR}$ ) accelerates complete closure of hard-to-heal venous ulcers. Wound Repair Regen. 1999;7(4):201-207.

2. Veves A, Falanga V, Armstrong DG, Abolinski ML. Graftskin, a human skin equivalent, is effective in management of non-infected neuropathic diabetic foot ulcers. Diabetes Care. 2001;24:290-295.

3. Marston WA, Hanft J, Norwood P, Pollak R, Dermagraft Diabetic Foot Ulcer Study Group. The efficacy and safety of Dermagraft in improving the healing of chronic diabetic foot ulcers: results of a prospective randomized trial. Diabetes Care. 2003;26(6):1701-1705.

4. Rakers S, Gebert M, Uppalapati S, et al. "Fish matters": the relevance of fish skin biology to investigative dermatology. Exp Dermatol. 2010;19(4):313-324.

5. Magnússon S, Baldursson BT, Kjartansson H, et al. [Decellularized fish skin: characteristics that support tissue repair]. Laeknabladid. 2015;101(12):567-573. Icelandic

6. Imai Y. Role of omega-3 PUFA-derived mediators, the protectins, in influenza virus infection. Biochim Biophys Acta. 1851;2015(4):496-502.

7. Mil-Homens D, Bernardes N, Fialho AM. The antibacterial properties of docosahexaenoic omega-3 fatty acid against the cystic fibrosis multiresistant pathogen Burkholderia cenocepacia. FEMS Microbiol Lett. 2012;328(1):61-69.

8. Serhan CN. Pro-resolving lipid mediators are leads for resolution physiology. Nature. 2014;510(7503):92-101.

9. Crapo PM, Gilbert TW, Badylak SF. An overview of tissue and whole organ decellularization processes. Biomaterials. 2011;32(12):3233-3243.

10. Trinh TT, Dünschede F, Vahl C-F, Dorweiler B. Marine omega3 wound matrix for the treatment of complicated wounds. Phlebologie. 2016;45(02):93-98.

11. Yang CK, Polanco TO, Lantis JC. A prospective, postmarket, compassionate clinical evaluation of a novel acellular fish-skin graft which contains omega-3 fatty acids for the closure of hard-to-heal lower extremity chronic ulcers. Wounds. 2016;28(4):112-118.

12. Baldursson BT, Kjartansson H, Konrádsdóttir F, et al. Healing rate and autoimmune safety of full-thickness wounds treated with fish skin acellular dermal matrix versus porcine small-intestine submucosa: a noninferiority study. Int J Low Extrem Wounds. 2015;14(1):37-43.

13. Lantis Ii JC, Petursdottir K, Baldursson B, Kirsner RS, Double-Bline WD. Prospective, randomized clinical trial on 170 acute wounds shows significantly faster healing rate with intact fish skin Compared to human amniotic membrane. Presentation at a conference. American Professional Wound Care Association (APWCA) sept 6-8, 2018 in Baltimore, MD, USA.
14. Magnusson S, Baldursson BT, Kjartansson H, Rolfsson O, Sigurjonsson GF. Regenerative and antibacterial properties of acellular fish skin grafts and human Amnion/Chorion membrane: implications for tissue preservation in combat casualty care. Mil Med. 2017;182(S1):383-388.

15. Lantis J, Baldursson B, Magnusson S, Kjartansson SG. Acellular fish skin graft for surgical, trauma, venous and arterial and diabetic wounds: a retrospective clinical study. Paper presented at: 17 th Congress of the Asian Society for Vascular Surgery; October 20-23, 2016; Singapore.

16. Margolis DJ, Allen-Taylor L, Hoffstad O, Berlin JA. Diabetic neuropathic foot ulcers: predicting which ones will not heal. Am J Med. 2003;115(8):627-631.

17. Lantis J, Magnusson S, Margolis DJ, Baldursson BT, Kjartansson G, Sigurjonsson G. Cost saving potential of acellular fish skin graft: a cost simulation study on diabetic foot ulcers. Paper presented at: 17 th Congress of the Asian Society for Vascular Surgery; October 20-23, 2016; Singapore.

18. Lantis J, Magnusson S, Baldursson B, Kjartansson H, Rolfsson O, Sigurjonsson G. Fish skin omega-3 PUFAs induce cell migration and transcription of ALOX15, a specialized pro-resolving mediator forming lipoxygenase. Paper presented at: SAWC Fall; October 20-22, 2017; Las Vegas, NV.

19. Garwood CS, Kim PJ, Matai V, et al. The use of bovine collagenglycosaminoglycan matrix for atypical lower extremity ulcers. Wounds. 2016;28(9):298-305.

20. NIH Fact Sheets - Burns and Traumatic Injury. [homepage on the Internet]. Bethesda, MD: National Institutes of Health [updated October 2010]. Available from: https://report.nih.gov/nihfactsheets/Pdfs/ BurnsandTraumaticInjury(NIGMS).pdf. Accessed October 1, 2018.

21. Stone R, Larson D, Wall J, et al. 522 omega-3 rich fish skin grafts reduce donor skin requirements for full thickness burns. J Burn Care Res. 2018;39(suppl_1):S234-S235.

22. Dorweilier B, Trinh TT, Dünschede F, et al. Die marine Omega 3 Wundmatrix zur Behandlung komplizierter Wunden. Gefasschirurgie. 2017;22(8):558-567. German

23. Clasen TJ, Libich E, Feldmann M. When the fish gives the thrustgranulation tissue in case of poor circulation. Wound Manag. 2017;11(4):183-186.

24. Cyrek A, Bernheim J, Junterman B, Paul A. Local wound therapy of a chronic resistant venous ulcer with Omega 3 wound matrix; an unconventional procedure for the therapy of chronic wounds. Phlebologie. 2017;46(6):353-357.

25. Winters $\mathrm{C}$. Wound dehiscence on a diabetic patient with hemophilia and high risk of further amputation successfully healed with omega 3 rich fish skin: a case report. Diabetic Foot J. 2018;21(3):146-206.

26. Fagerdahl A. [Wound care with cod skin]. Sarmagasinet. 2017;34-36. Swedish

27. Alam K, Jeffery SLA. Acellular fish skin grafts for management of split thickness donor sites and partial thickness burns: a case series. Military Medicine. 2019;184(1):16-20.
Chronic Wound Care Management and Research

Publish your work in this journal

Chronic Wound Care Management and Research is an international, peer reviewed, open access, online journal publishing original research, reviews, editorials, and commentaries on the causes and management of chronic wounds and the major issues related to chronic wound management. Topics also include chronic wounds as comorbidities to other

\section{Dovepress}

conditions, patient adherence to therapy, and the economic burden of chronic wounds. The manuscript management system is completely online and includes a very quick and fair peer review system, which is all easy to use. Visit http://www.dovepress.com/testimonials.php to read real quotes from published authors. 